\title{
PENERAPAN SISTEM INFORMASI AKADEMIK (SIA) SEBAGAI UPAYA PENINGKATAN EFEKTIFITAS DAN EFISIENSI PENGELOLAAN AKADEMIK SEKOLAH
}

\author{
Riyadi Purwanto ${ }^{1}$ \\ ${ }^{1}$ Program Studi Teknik Informatika, Politeknik Negeri Cilacap \\ J1. Dr. Soetomo, No.1 Sidakaya Cilacap, Jawa Tengah \\ email : adidok_bayu@yahoo.com ${ }^{1}$
}

\begin{abstract}
Abstrak
Teknologi Informasi telah memberikan peran penting sebagai media informasi dan komunikasi dalam bidang pendidikan, salah satunya dalam Pengelolaan Akademik Sekolah. Penerapan Sistem Informasi Akademik sebagai satu cara dalam upaya peningkatan efektifitas dan efisiensi pengelolaan akademik meliputi pendaftaran siswa baru, pengelolaan data siswa dan guru, pengelolaan jadwal pelajaran, dan pengolahan nilai siswa. Sistem Informasi Akademik dikembangkan sebagai layanan informasi berupa data-data yang berhubungan dengan data akademik. Dalam pengembangan Sistem Informasi Akademik, metodologi yang dapat digunakan adalah metodologi Waterfall yang terdiri dari beberapa tahapan antara lain : ${ }^{1}$ )Tahap planing yaitu membahas perencanaan sistem yang akan dikembangkan, ${ }^{2}$ )Tahap Analisis yaitu melakukan analisis sistem yang berjalan serta analisis kebutuhan fungsional dan non fungsionalnya , ${ }^{3}$ )Tahap Desain yaitu merancang dan mendesain sistem, dan ${ }^{4}$ )Tahap Implementasi yaitu produksi aplikasi dan testing. Hasil penelitian menunjukan bahwa Sistem Informasi Akademik dapat meningkatkan efektifitas dan Efisiensi Pengelolaan Akademik Sekolah. Dari sisi efektififitas, sistem informasi akademik dapat digunakan untuk meningkatkan komunikasi dan mengorganisir data akademik secara tepat dan akurat, sedangkan dari sisi efisiensi, sistem informasi akademik dapat mempercepat proses pengelolaan akademik, mengurangi biaya operasional (low cost dan paper less) serta mengurangi human error dalam pengolahan nilai siswa.
\end{abstract}

Kata kunci : Sistem Informasi Akademik, Efektifitas dan efisiensi penerapan Sistem Informasi Akademik.

\begin{abstract}
Information Technology has provided an important role as a medium of information and communication in the field of education, one of them in School Academic Management. Implementation of Academic Information System as one way to increase effectiveness and efficiency of academic management include new student enrollment, student and teacher data management, management of lesson schedule, and student value processing. Academic Information System developed as an information service in the form of data related to academic data. In the development of Academic Information System, the methodology that can be used is Waterfall methodology which consists of several stages, among others: $\left.{ }^{1}\right)$ Planing stage that is discussing the planning of the system to be developed, $\left.{ }^{2}\right)$ Stage Analysis is to analyze the running system and the analysis of functional and non functional needs, $\left.{ }^{3}\right)$ Design stage that is designing and designing system, and $\left.{ }^{4}\right)$ Implementation Phase that is production of application and testing.The results showed that Academic Information System can improve the effectiveness and Efficiency of School Academic Management. In terms of effectiveness, academic information system can be used to improve communication and organize academic data accurately and accurately, while in terms of efficiency, academic information system can accelerate the academic management process, reduce operational costs (low cost and paper less) and reduce human error in processing student value.
\end{abstract}

Keywords : Academic Information System, SIA, Effectiveness and efficiency of application of Academic Information System. 


\section{Pendahuluan}

\subsection{Latar Belakang}

Teknologi Informasi telah memberikan peran penting sebagai media informasi dan komunikasi dalam bidang pendidikan. Salah satu peran tersebut adalah pengelolaan akademik sekolah. Akademik adalah suatu bidang yang mempelajari tentang kurikulum atau pembelajaran dalam fungsinya untuk meningkatkan pengetahuan dalam segi pendidikan / pembelajaran yang dapat dikelola oleh suatu sekolah atau lembaga pendidikan [7].

Pengelolaan Akademik dapat diimplementasikan dengan menerapkan Sistem Informasi Akademik (SIA). Sistem informasi akademik adalah sistem yang memberikan layanan informasi yang berupa data dalam hal yang berhubungan dengan data akademik [10].

SMP Negeri 2 Paguyangan merupakan salah satusatunya Sekolah Menengah Pertama di Desa Pandansari, Kecamatan Paguyangan, Kabupaten Brebes. Terletak didataran tinggi (pegunungan) dengan ketinggian $1500 \mathrm{~s} / \mathrm{d} 2050 \mathrm{~m}$ diatas permukaan laut dan suhu antara $8 \mathrm{~s} / \mathrm{d} 28$ decarajat celcius. Jarak tempuh $\pm 15 \mathrm{~km}$ dari pusat kota dan kecamatan. Saat ini jumlah siswa aktif \pm 440 siswa. Terdapat 11 kelas dan masing-maing kelas ditempati \pm 40 siswa.

Pengelolaan akademik sekolah di SMP Negeri 2 Paguyangan saat ini masih dilakukan secara konvensional. Pendaftaran siswa baru masih dilakukan secara manual dengan menggunakan formulir pendaftaran, pengisian nilai raport dan perhitungan nilai raport masih dilakukan secara manual oleh masing-masing guru, pengelolaan data siswa dan guru masih dilakukan dengan menggunakan buku Induk.

Sistem Pengelolaan Akademik yang berjalan saat ini dirasakan menimbulkan beberapa permasalahan, antara lain : ${ }^{1}$ )Perhitungan nilai raport sering terjadi kesalahan (human error) cukup tinggi, ${ }^{2}$ )Pencarian data siswa dalam buku induk memerlukan waktu yang lama (tidak efisien), ${ }^{3}$ )Pendaftaran siswa baru dengan pengisian formulir tidak efektif karena rekap data pendaftaran siswa baru harus dicatat lagi dalam buku induk (dua kali kerja).

Berdasarkan permasalahan-permasalahan yang ada, maka untuk dapat meningkatkan efektifitas dan efisiensi pengelolaan akademik diperlukan sebuah Sistem Informasi Akademik (SIA) yang diterapkan di sekolah tersebut. Beberapa fungsi utama yang perlu dikembangkan dalam sistem tersebut antara lain : $\left.{ }^{1}\right)$ Pendaftaran siswa baru secara online, $\left.{ }^{2}\right)$ Pengelolaan data siswa dan guru, $\left.{ }^{3}\right)$ Pengisian dan perhitungan nilai raport yang dapat dilakukan oleh guru dan wali kelas secara online, ${ }^{4}$ )Akses hasil prestasi siswa yang dapat diakses oleh orang tua dan siswa secara online. Dengan adanya sistem tersebut, diharapkan pengelolaan Akademik di SMP Negeri 2 Paguyangan menjadi lebih baik dan terorganisir, proses pendaftaran siswa baru dan pengelolaan data siswa dapat terintegrasi (paper less), pencarian data siswa menjadi lebih cepat, pengisian dan perhitungan nilai raport lebih jelas dan akurat mengurangi (human error). Oleh karena itu, tujuan dari penelitian ini adalah mengembangkan Sistem Informasi Akademik (SIA) untuk diterapkan di SMP Negeri 2 Paguyangan sehingga dapat meningkatkan efektifitas dan efisiensi Pengelolaan Akadmik.

\subsection{Tujuan Peniltian}

Tujuan dari penelitian yang dilakukan adalah mengembangkan Sistem Informasi Akademik (SIA) untuk diterapkan di sekolah sehingga dapat meningkatkan efektifitas dan efisiensi Pengelolaan Akadmik.

\subsection{Manfaat Penelitian}

Manfaat dari penelitian yang dilakukan adalah sebagai berikut :

a) Mempermudah guru dalam pengisian dan perhitungan nilai raport sehingga dapat mengurangi (human error)

b) Mempermudah proses pendaftaran siswa baru dan mengurangi cost operational dalam hal (paper less)

c) Pengelolaan data siswa dan guru menjadi lebih terorganisir, efektif dan efisien

\subsection{Tinjauan Pustaka}

Menurut Membara. E.P. dkk [12] Sistem informasi merupakan kombinasi teratur dari orangorang, perangkat keras (hardware), perangkat lunak (sofware), jaringan komunikasi dan sumber daya data yang menggumpulkan, mengubah dan menyebarkan informasi dalam sebuah organisasi.

Menurut Membara. E.P. dkk [9] Sistem informasi merupakan suatu sistem yang terdiri dari brainware, data dan prosedur untuk menjalankan input, proses output, pernyimpinan dan pengontrolan yang mengubah sumber dan menjadi informasi.

Menurut Kurnia. T., dkk [6] Sistem informasi didefinisikan oleh Leitch dan Davis dalam Jogiyanto (2005), sistem informasi adalah suatu sistem di dalam suatu organisasi yang mempertemukan kebutuhan pengolahan transaksi harian, mendukung operasi, bersifat manajerial dan kegiatan strategi dari suatu organisasi dan menyediakan pihak luar tertentu dengan laporanlaporan yang diperlukan.

Membara, E.P.,dkk [9] menjelaskan bahwa sistem informasi berbasisi komputer (CBIS) dalam suatu organisasi terdiri dari komponen-komponen berikut [1]:

1) Perangkat keras, yaitu perangkat keras komponen untuk melengkapi kegiatan memasukkan data, memproses data dan keluaran data.

2) Perangkat lunak, yaitu program dan instruksi yang diberikan ke komputer. 
3) Database, yaitu kompulan data dan informasi yang diorganisasikan sedemikian rupa sehingga mudah diakses penggunaan sistem informasi.

4) Telekomunikasi, yaitu komunikasi yang menghubungkan antara pengguna sistem dengan sistem komputer secara bersama-sama kedalam suatu jaringan kerja yang efektif.

5) Manusia, yaitu personel dari sistem informasi, meliputi menejer, analisis, programmer, operator serta bertanggung jawab terhadap perawatan sistem.

Menurut Alpiandi.M.R. [7] Akademik adalah suatu bidang yang mempelajari tentang kurikulum atau pembelajaran dalam fungsinya untuk meningkatkan pengetahuan dalam segi pendidikan / pembelajaran yang dapat dikelola oleh suatu sekolah atau lembaga pendidikan Akademik juga dapat didefinisikan keadaan orang-orang bisa menyampaikan dan menerima gagasan, pemikiran, ilmu pengetahuan, dan sekaligus dapat mengujinya secara jujur, terbuka, dan leluasa [5].

Membara E.P., dkk. menjelaskan dapat dikatakan bahwa secara umum pengertian akademik berarti proses belajar mengajar yang dilakukan di kelas atau dunia persekolahan. Kegiatan akademik meliputi tugas-tugas yang dinyatakan dalam program pembelajaran, diskusi, obeservasi, dan pengerjaan tugas. Dalam satu kegiatan akademik diperhitungkan tidak hanya kegiatan tatap muka yang terjadwal saja tetapi juga kegiatan yang direncanakan (terstruktur) dan yang dilakukan secara mandiri[9].

Dengan demikian Alpiandi. M.R. menyimpulkan Sistem informasi akademik adalah sistem yang memberikan layanan informasi yang berupa data dalam hal yang berhubungan dengan data akademik[10].

Menurut Suzanto dan Sidharta, Sistem informasi akedemik merupakan bagian dari pengendalian internal suatu kegiatan akademik yang meliputi pemanfaatan sumber daya manusia, dokumen, teknologi, dan prosedur oleh manajemen untuk memecahkan masalah akademik. Sistem informasi akademik ini merupakam sistem informasi berdasarkan pada aktivitas manajemen. Sistem ini menggunakan perangkat keras (hardware) dan perangkat lunak (software) komputer, prosedur pedoman, model manajemen dan keputusan, dan sebuah "data base"[11].

\section{Metodologi Penelitian}

Dalam proses pengembangan Sistem Informasi Akademik, peneliti mengacu pada metode pengembangan perangkat lunak secara umum, yaitu metode pengembangan System Development Life Cycle (SDLC). Metode ini berfungsi untuk mengembangkan, memelihara dan menggunakan sistem yang mencakup sejumlah fase atau tahapan.

Menurut Connoly (2005, h. 284), tahapan SDLC tidak mutlak dilaksanakan secara terurut, melainkan melalui sejumlah perulangan dari tahapan terdahulu agar didapatkan hasil yang maksimal sebagaimana terlihat pada Gambar 1.

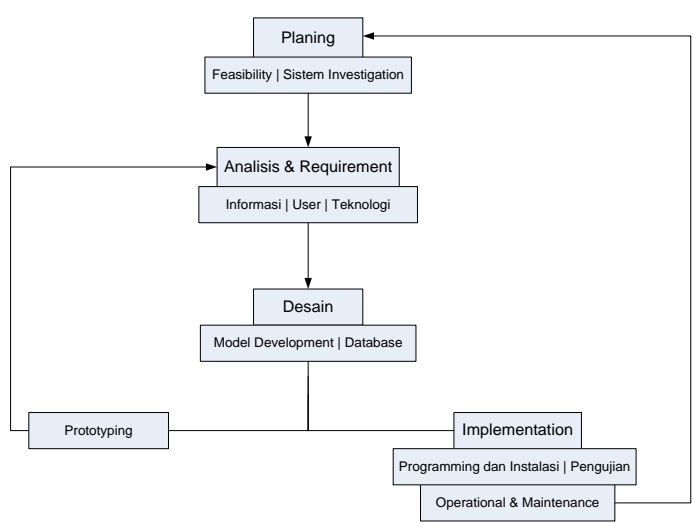

Gambar 1. Metode pengembangan SDLC [4]

Metode pengembangan SDLC terdiri dari beberapa fase/tahapan. Metode tersebut akan digunakan dalam pengembangan "Sistem Informasi Akademik SMP Negeri 2 Paguyangan".

1) Tahap Planing

Dalam tahap planing terdapat 2 langkah yaitu :

a. Feasibility berupa mengindentifikasi masalah, menentukan tujuan sistem, dan memebuat studi kelayakan (teknik, operasional dan jadwal).

b. Sistem investigasi berupa dan observasi dan wawancara.

2) Tahap Analisis \& Requirement

Dalam tahap analisis dibagi menjadi beberapa langkah antara lain :

a. Analisis informasi yaitu mengenai SMP Negeri 2 Paguyangan dan proses pengelolaan Akademik yang telah berjalan.

b. Analisis user yaitu menentukan kebutuhan user, dalam arti mengidentifikasi user yang akan menggunakan sistem.

c. Analisis teknologi yaitu menentukan kebutuhankebutuhan sistem baik dari software maupun hardware

3) Tahap Desain

Pada tahap desain terdapat beberapa tahap, antara lain:

a. Model development merupakan model yang akan digunakan sebagai arsitektur sistem. Model ini menggambarkan relationship (hubungan) dari sistem keseluruhan, antara semua fungsi dalam module yang terpisah, perubahan atau perpindahan data dari module dalam sistem.

b. Desain database merupakan hubungan relasi antara Tabel dapat berupa normalisasi, dan menggambarkan secara detail masukan dan keluaran data. 


\section{4). Tahap Implementation}

Hasil dari implementation berupa prototyiping software. Prototype diuji dan disempurnakan sebelum dilakukan software tersebut diimplementasikan atau digunakan. Dalam software engineering, pembuatan prototype merupakan suatu proses produksi.

\section{Perancangan Sistem}

Dalam sistem yang dikembangkan terdapat beberapa proses utama, antara lain:

a. Proses Pendaftaran Siswa Baru

b. Proses Pengelolaan Data Siswa dan Guru

c. Proses Pengisian dan perhitungan nilai raport

Proses-proses utama dalam Sistem Informasi Akademik SMP Negeri 2 Paguyangan dapat digambarkan dalam bentuk Context Diagram dan Data Flow Diagram sebagai berikut :

\subsection{Konteks Diagram}

Secara umum Rancangan Sistem Informasi Akademik SMP Negeri 2 Paguyangan dapat digambarkan dalam Konteks diagram sebagai berikut :

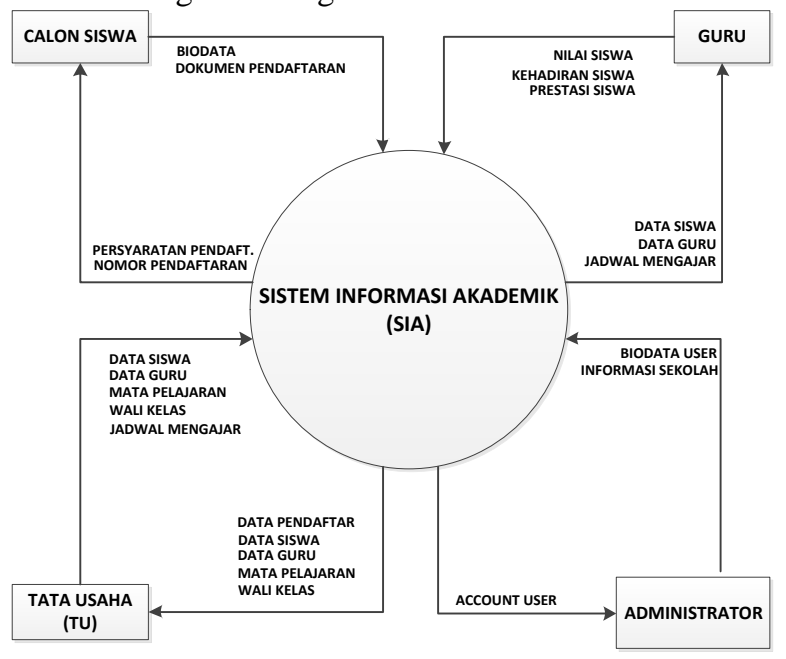

Gambar 2. Konteks Diagram SIA

Gambar 2. menjelaskan tentang gambaran secara umum Sistem Infomasi Akademik SMP Negeri 2 Paguyangan yang dapat dijelaskan sebagai berikut:

1) Terdapat 4 (empat) aktor dalam Sistem Informasi Akademik SMP Negeri 2 Paguyangan yang akan mempergunakan atau memanfaatkan sistem tersebut, antara lain : Administrator, Calon Siswa (pendaftar), Bagian Tata Usaha (TU), dan Guru.

2) Terdapat beberapa aliran data dari masing-masing aktor baik dari Aktor terhadap sistem maupun dari sistem terhadap masing-masing aktor sesuai dengan Autorization System (hak akses).

\subsection{Data Flow Diagram (DFD) Level 0}

Konteks Diagram yang telah dijelaskan pada gambar 2, akan diturunkan menjadi Data Flow Diagram Level 0 yang dapat digambarkan sebagai berikut :

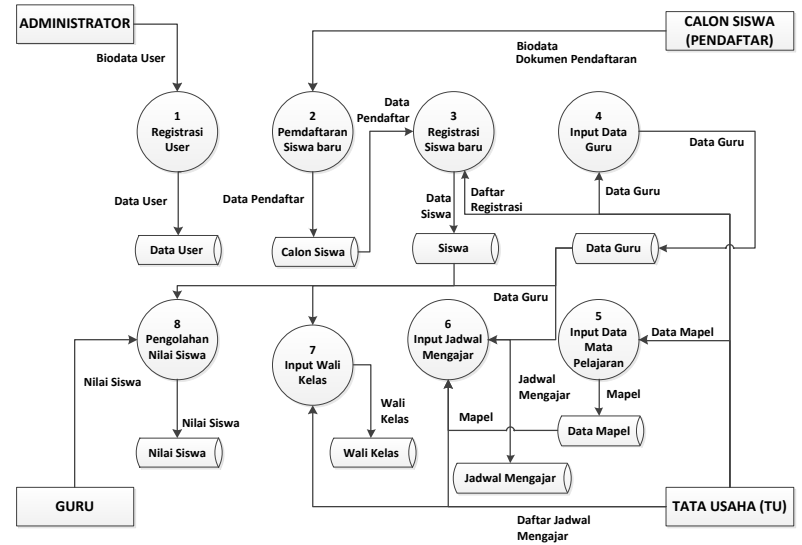

Gambar 3. DFD Level 0 SIA

Gambar 3. menjelaskan proses-proses utama yang akan dikembangkan dalan Sistem Informasi Akademik SMP Negeri 2 Paguyangan yang dapat dijelaskan sebagai berikut:

Dalam sistem yang dikembangkan terdapat 8 (delapan) proses utama, antara lain :

1) Proses registrasi user yang dilakukan oleh Administrator. Dalam hal ini user yang akan mengakses sistem antara lain, Administrator, Bagian Tata Usaha (TU), Calon Siswa (Pendaftar), dan Guru.

2) Proses pendaftaran siswa baru dilakukan oleh calon siswa sebagai pendaftar yang dilakukan secara online dalam lingkup Local Arean Network (LAN).

3) Proses registrasi siswa baru dilakukan oleh Bagian Tata Usaha (TU) selaku pengelola Akademik di SMP Negeri 2 Paguyangan. Proses ini dilakukan dengan memperhatikan siswa yang lolos seleksi dan calon siswa yang melakukan registrasi/pendaftaran ulang.

4) Proses input data guru dilakukan oleh Bagian Tata Usaha (TU). Petugas tersebut menginputkan biodata dan Kelompok Bidang Keahlian (KBK) yang dimiliki oleh masing-masing guru.

5) Proses input mata pelajaran dilakukan oleh Bagian Tata Usaha (TU) selaku pengelola akademik di SMP Negeri 2 Paguyangan.

6) Proses input jadwal mengajar dilakukan oleh Bagian Tata Usaha (TU). Proses tersebut dilakukan dengan memperhatikan daftar guru sesuai dengan KBK dan beban mengajar masingmasing guru.

7) Proses Input wali kelas dilakukan oleh Bagian Tata Usaha (TU). Setiap kelas memiliki guru yang bertugas atau bertanggungjawab sebagai wali kelas.

8) Proses pengolahan nilai dilakukan oleh guru. Setiap guru memasukan nilai pada masing-masing mata pelajaran yang diampunya. 
3.3 DFD Level 1 Proses Pengolahan Nilai

Untuk dapat meilhat proses pengolahan nilai seperti yang terlihat pada DFD Level 0 pada gambar 3, maka proses pengolahan nilai dapat diturunkan menjadi DFD Level 1 Proses pengolahan nilai seperti yang terlihat pada gambar 4.

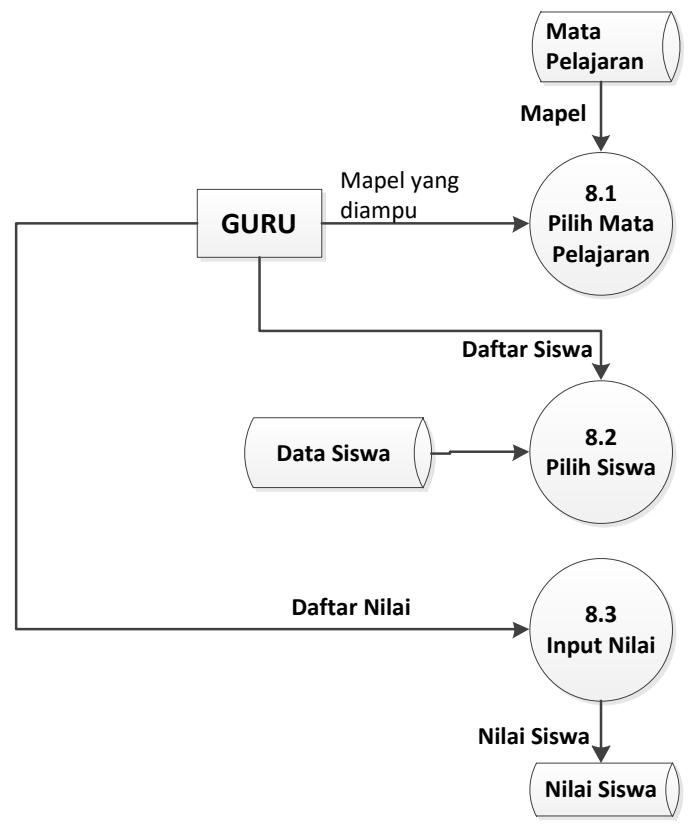

DFD Level 1 Proses Pengolahan Nilai

Gambar 4. Menjelaskan proses pengolahan nilai yang diturunkan menjadi Level 1. Proses tersebut dapat dijelaskan sebagai berikut :

1) Pada DFD Level 1 Proses pengolahan nilai hanya terdapat 1 (satu) aktor, yaitu Guru. Aktor tersebut memiliki kewengan terhadap pengolahan nilai siswa.

2) Proses pengolahan nilai seperti yang terlihat pada DFD Level 0 SIA gambar 3, diturunkan menjadi 3 proses, yaitu : proses pilih mata pelajaran, proses pilih siswa, dan proses input nilai. Proses-proses tersebut dilakukan secara bertahap.

\subsection{Entitas Relationship Diagram (ERD)}

Untuk menjelaskan hubungan (relasi) satu aktor/entitas dengan aktor/entitas lainnya dalam Sistem Informasi Akademik SMP Negeri 2 Paguyangan, maka perlu dibuat Entitas Relationship Diagram (ERD) seperti yang terlihat pada gambar 5 .

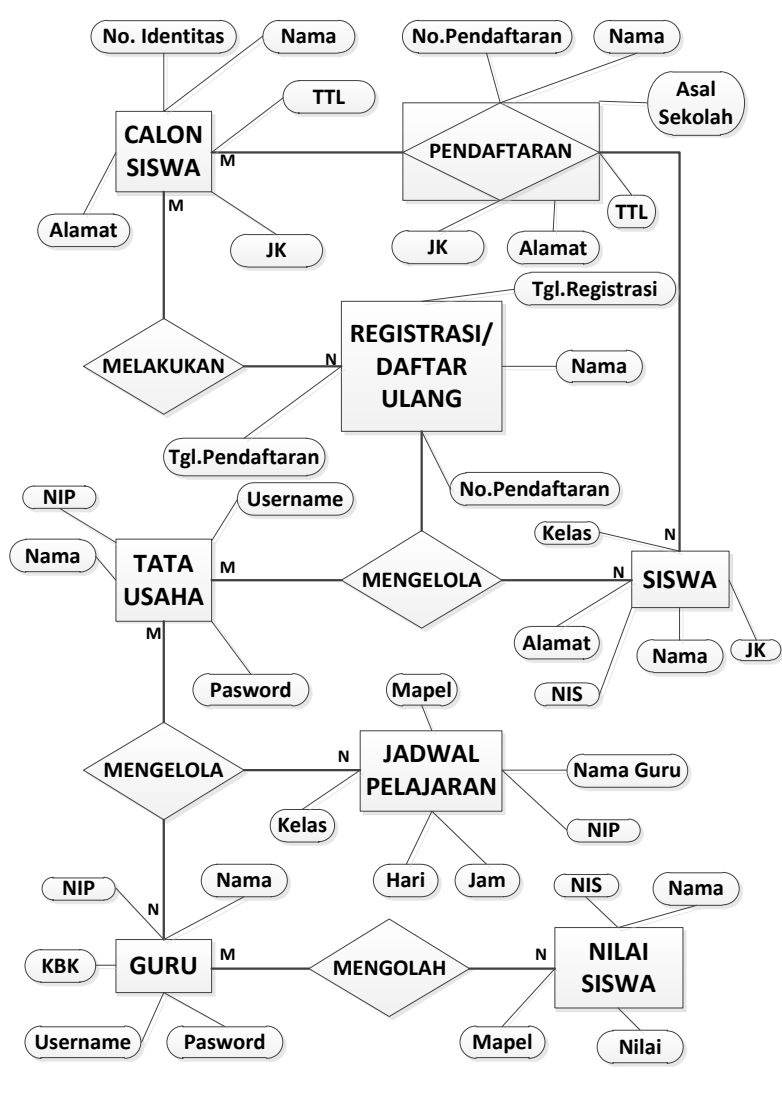

Gambar 5. Entitas Relationship Diagram (ERD)

Gambar 5. Menjelaskan hubungan (relationship) antar entitas dalam Sistem Informasi Akademik yang dapat dijelaskan sebagai berikut :

1) Terdapat 7 entitas yang saling berhubungan atau memiliki relationship yaitu : Siswa, Tata Usaha, Pendaftaran, Registrasi, Siswa, Jadwal Pelajaran, Guru, dan Siswa.

2) Masing-masing entitas memiliki kardinalitas (M : $\mathrm{N})$.

3) Terdapat satu entitas asosiatif yaitu entitas Pendaftaran.

\section{Hasil Penelitian dan Pembahasan}

\subsection{Hasil Penelitian}

Hasil penelitian yang dilakukan adalah berupa Sistem Informasi Akademik SMP Negeri 2 Paguyangan. Sistem yang kembangkan dapat digunakan sebagai media untuk mengelola Akademik pada sekolahan tersebut.

Dalam sistem yang dikembangkan terdapat beberapa proses utama yang diimplementasikan, antara lain:

1) Proses pendaftaran siswa baru secara online dalam lingkup local area network (LAN)

2) Proses pengelolaan data siswa dan guru

3) Proses pengelolaan jadwal pelajaran

4) Proses pengolahan nilai siswa 


\subsection{Pembahasan}

Dari hasil penelitian yang telah dicapai, maka selanjutnya akan dilakukan pembahasan sebagai berikut :

\subsubsection{Proses Pendaftaran Siswa}

Proses pendaftaran siswa baru merupakan salah satu proses pertama yang dilakukan oleh siswa sebelum diterima dan ditetapkan sebagai siswa SMP Negeri 2 Paguyangan. Dalam sistem yang dikembangkan, proses ini dilakukan oleh calon siswa/orang tua wali secara online dalam lingkup local area Network (LAN) pada sekolahan tersebut.

Peroses pendaftaran online terlihat pada gambar 6.

\section{FORM PENDAFTARAN SISWA BARU}

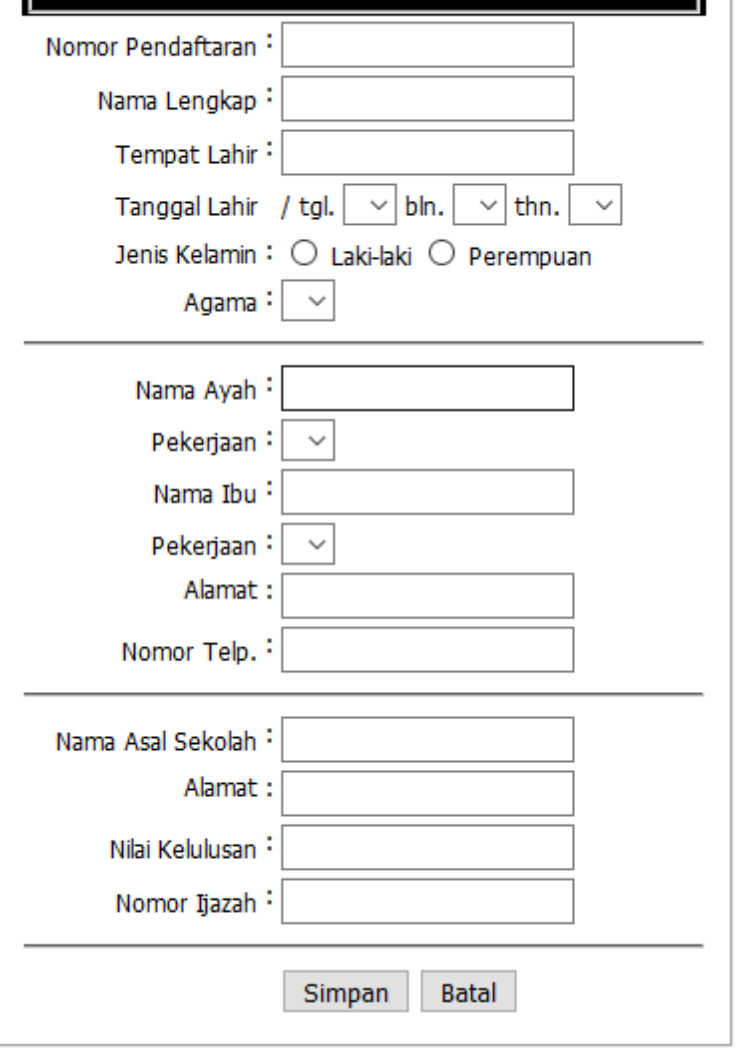

Gambar 6. Form Pendaftaran Siswa baru

Pada isian form pendaftaran siswa baru seperti yang terlihat pada gambar 6 terdapat beberapa isian, antara lain : data pendaftar, data orang tua, dan data sekolah asal. Berkas dokumen pendukung seperti ijazah dan lain-lain diserahkan secara manual kepada petugas.

\subsubsection{Proses pengelolaan data siswa dan guru}

Proses pengelolaan data siswa dan guru merupakan aktivitas pencatatan data baik siswa maupun guru dalam sebuah database yang dilakukan oleh bagian Tata Usaha (TU). Apabila terdapat penambahan dan pengurangan siswa ataupun penambahan dan mutasi/perpindahan guru, maka Bagian Tata Usaha dapa melakukan perubahan data pada sistem ini. Tampilan data siswa dan guru terlihat pada gambar 7 dan gambar 8.

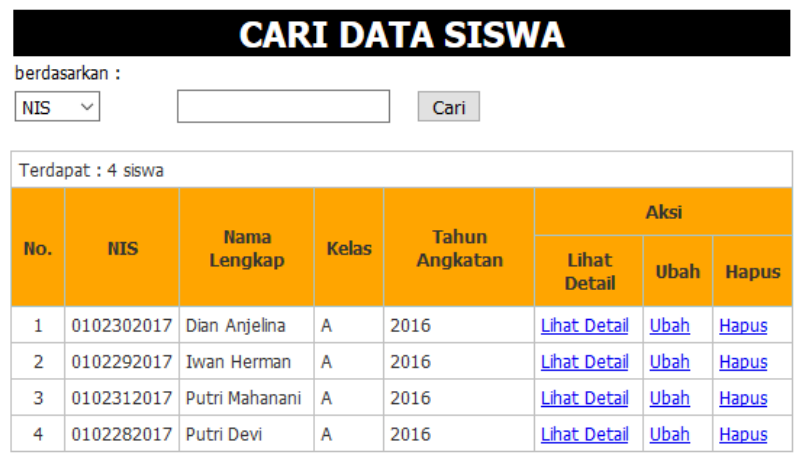

Gambar 7. Tampilan data siswa

Gambar 7. Menunjukan tampilan data siswa SMP Negeri 2 Paguyangan. Terdapat tampilan cari data untuk mencari data berdasarkan kategori tertentu yaitu bersasarkan NIS, nama siswa, dan kelas. Disamping itu unfuk dapat melakukan perubahan atau update data terdapat link ubah. Untuk melihat informasi data siswa secara detail terdapat link lihat detail. Untuk menghapus data terdapat link hapus.

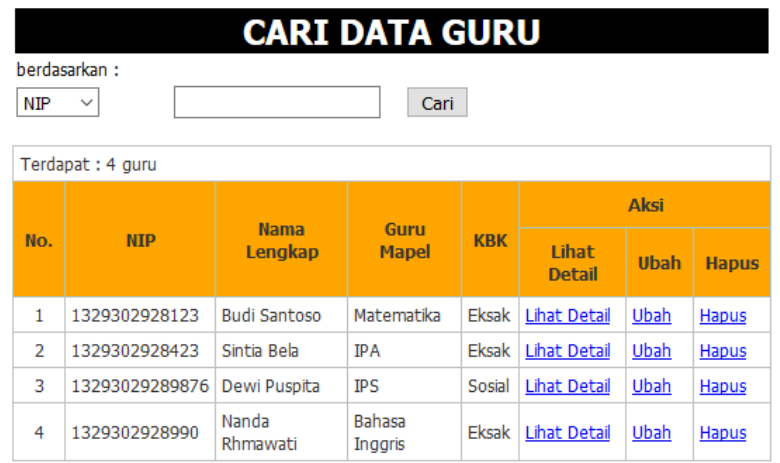

Gambar 8. Tampilan data guru

Gambar 8. Menunjukan tampilan data guru SMP Negeri 2 Paguyangan. Terdapat tampilan cari data untuk mencari data berdasarkan kategori tertentu yaitu bersasarkan NIP dan nama guru. Disamping itu unfuk dapat melakukan perubahan atau update data terdapat link ubah. Untuk melihat informasi data siswa secara detail terdapat link lihat detail. Untuk menghapus data terdapat link hapus. Salah satu contoh tampilan lihat detail data guru terlihat pada gambar 9 .

\section{DATA GURU}

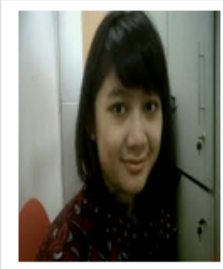

$\begin{array}{ll}\text { NIP } & : 13293029289876 \\ \text { Nama Lengkap } & : \text { Dewi Puspita } \\ \text { Guru Mata Pelajaran } & : \text { IPS } \\ \text { KBK } & : \text { Sosial } \\ \text { No.telp } & : 065435425627 \\ \text { Email } & \text { :dewi@yahoo.com }\end{array}$

Gambar 9. Tampilan detail data guru 
4.2.3 Proses pengelolaan jadwal pelajaran

Dalam sistem yang dikembangkan, pengelolaan jadwal pelajaran dilakukan oleh bagian Tata Usaha yang bertugas dalam bidang akademik.Tampilan jadwal pelajaran terlihat pada gambar 10 .

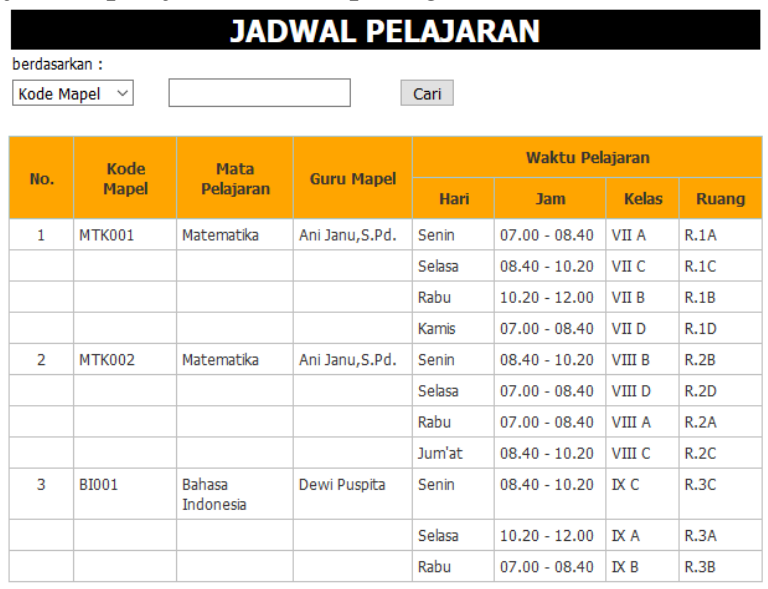

Gambar 10. Jadwal Pelajaran

Gambar 10. Menunjukan informasi jadwal pelajaran masing-masing mata pelajaran berdasarkan guru mapel. Dalam sistem tersebut diberikan fitur cari data berdasarkan kode mapel, nama mapel, dan guru mapel, sehingga mempermudah dan mempercepat proses pencarian data.

\subsubsection{Proses Pengolahan nilai siswa}

Pengolahan nilai siswa merupakan salah satu proses utama dalam Sistem Informasi Akademik yang dikembangkan. Pengolahan nilai dilakukan oleh guru yang dengan mengisi nilai siswa berdasarkan mata pelajaran yang diampunya. Dengan demikian guru tidak perlu lagi menyerahkan nilai kepada wali kelas secara manual baik dalam hardcopy maupun softcopy, akan tetapi guru dapat mengisi langsung nilai siswa dalam Sistem Informasi Akademik. Tampilan pengisian nilai siswa terlihat pada gambar 11 .

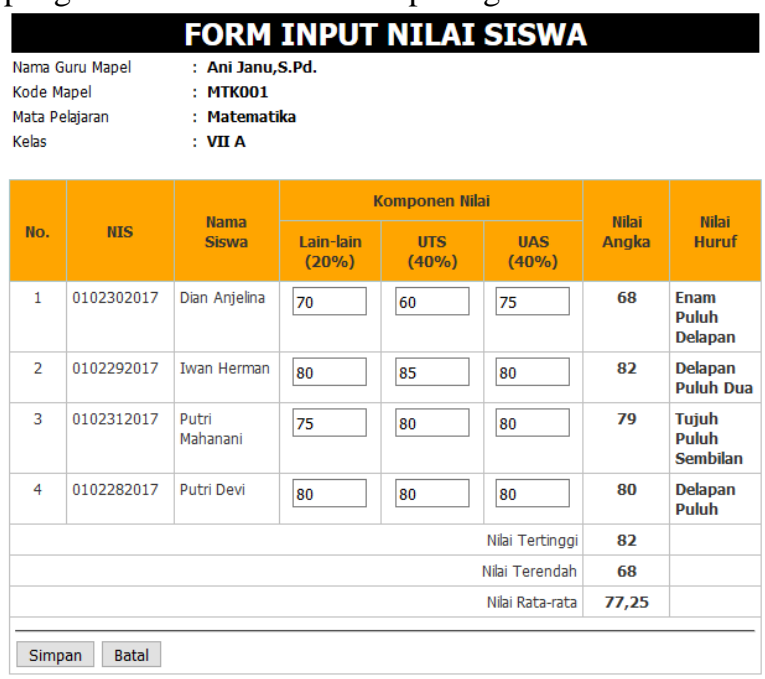

Gambar 11. Form input nilai siswa

Gambar 11 menunjukan form tampilan input nilai siswa yang dapat dilakukan oleh masing-masing guru berdasarkan mata pelajaran yang diampunya. Form tersebut terdiri dari 3 komponen penilaian yaitu :

a) Lain-lain sebesar $20 \%$ meliputi (nilai ulangan, keaktifan, nilai PR, nilai kehadiran)

b) Nilai UTS sebesar $40 \%$

c) Nilai UAS sebesar $40 \%$

Dalam sistem yang dikembangkan, perhitungan komponen nilai lain-lain masih dilakukan diluar sistem. Hal ini dikarenakan kuantitas nilai ulangan dan nilai PR dari masing-masing guru berbeda-beda.

\subsection{Pengujian Sistem}

Untuk dapat melihat fungsi sistem berjalan dengan baik dan sesuai dengan perencanaan dan kebutuhan fungsional, maka perlu dilakukan pengujian sistem. Pengujian sistem dilakukan dengan menggunakan metode pengujian black box testing. Metode black box testing adalah pengujian yang dilakukan hanya mengamati hasil eksekusi melalui data uji dan memeriksa fungsional dari perangkat lunak. Skenario hasil pengujian sistem adalah sebagai berikut :

Tabel 1. Skenario hasil pengujian sistem

\begin{tabular}{|c|c|c|c|}
\hline No. & $\begin{array}{l}\text { Fungsi } \\
\text { Sistem }\end{array}$ & Butir uji & $\begin{array}{l}\text { Hasil } \\
\text { Pengujian }\end{array}$ \\
\hline \multirow[t]{2}{*}{1.} & \multirow{2}{*}{$\begin{array}{l}\text { Pendaftaran } \\
\text { siswa baru } \\
\text { secara online }\end{array}$} & Login user & Berhasil \\
\hline & & $\begin{array}{l}\text { Input data } \\
\text { pendaftaran }\end{array}$ & Berhasil \\
\hline \multirow[t]{2}{*}{2.} & \multirow{2}{*}{$\begin{array}{l}\text { Pengelolaan } \\
\text { data siswa } \\
\text { dan guru }\end{array}$} & Login user & Berhasil \\
\hline & & $\begin{array}{l}\text { Input, Ubah, } \\
\text { Hapus data siswa } \\
\text { dan guru }\end{array}$ & Berhasil \\
\hline \multirow[t]{3}{*}{3.} & \multirow{3}{*}{$\begin{array}{l}\text { Pengolahan } \\
\text { Jadwal } \\
\text { Pelajaran }\end{array}$} & Login user & Berhasil \\
\hline & & $\begin{array}{l}\text { Input, Ubah, } \\
\text { Hapus jadwal } \\
\text { pelajaran }\end{array}$ & Berhasil \\
\hline & & $\begin{array}{l}\text { Sistem dapat } \\
\text { memberikan } \\
\text { notifikasi bila ada } \\
\text { jadwal pelajaran } \\
\text { berbeda dalam } \\
\text { waktu yang sama }\end{array}$ & Berhasil \\
\hline \multirow[t]{4}{*}{4.} & \multirow{4}{*}{$\begin{array}{l}\text { Pengelolaan } \\
\text { Nilai Siswa }\end{array}$} & Login user & Berhasil \\
\hline & & $\begin{array}{l}\text { Input, Ubah, } \\
\text { Hapus Nilai } \\
\text { Siswa }\end{array}$ & Berhasil \\
\hline & & $\begin{array}{l}\text { Hitung dan rekap } \\
\text { nilai siswa }\end{array}$ & Berhasil \\
\hline & & Akses nilai siswa & Berhasil \\
\hline
\end{tabular}

\section{Kesimpulan dan Saran}

Berdasarkan hasil penelitian tentang pengembangan Sistem Informasi Akademik Sekolah, maka dapat dibuat kesimpulan sebagai berikut :

1) Berdasarkan hasil pengujian, sistem yang dikembangkan dapat membantu pengelolaan akademik di SMP Negeri 2 Paguyangan.

2) Penerapan Sistem Informasi Akademik dapat meningkatkan efektifitas dan efisiensi pengelolaan Akademik. 
a) Dari sisi efektifitas, pendaftaran siswa baru dapat dilakukan secara online, sehingga data tercatat dalam database. Pada saat calon siswa melakukan registrasi ulang, maka petugas akademik (TU) tidak perlu lagi mencatat ulang atau dua kali kerja. Disamping itu dengan SIA yang dikembangkan, guru dapat mengakses langsung form isian nilai siswa dalam aplikasi SIA. Dengan demikian, proses pengisian nilai siswa dapat dilakukan dapat dilakukan kapanpun. Guru tidak perlu lagi menyerahkan nilai dalam bentuk hardcopy ataupun softcopy kepada wali kelas.

b) Dari sisi efisiensi, Sistem Informasi Akademik dapat mengurangi cost operational (low cost) dan paper less. Proses pengelolaan data siswa dan guru , pengolahan jadwal pelajaran serta pengolahan nilai siswa menjadi lebih cepat dan tepat.

3) Perhitungan nilai siswa dengan menggunakan Sistem Informasi Akademik lebih akurat dan tepat, sehingga dapat mengurangi (human error).

Disamping itu, agar penelitian yang dilakukan dapat menjadi lebih optimal lagi, maka penulis memberikan saran bahwa Sistem Informasi Akademik yang dikembangkan tidak mengakomodir pengelolaan keuangan. Oleh karena itu, diharapkan penelitian ini dikembangkan lagi agar dapat mengakomodir pengelolaan keuangan.

\section{Daftar Pustaka :}

[1] Al fatta, Hanif .2007. Analisa dan Perancangan Sistem Informasi Umtuk Keunggulan Bersaing Perusahaan Dan Organisasi Moderen. Andi Offset : Yogyakarta.

[2] Alpiandi.M.R. 2016. Sistem Informasi Akademik Berbasis Web Di Smp Negeri 2 Kecamatan Gaung Anak Serka. Jurnal SISTEMASI. Vol.5, No. 3, hal.8-13. ISSN : 2302-8149, EISSN:2540-9717.

[3] Alpiani, Rizki. (2016). Sistem Informasi Akademik Berbasis Web Di Smp Negeri 2 Kecamatan Gaung Anak Serka. Vol. 5, No. 3. Hal. 8 -13.

[4] Connolly, Thomas; \& Begg, Carolyn. (2005). Database System, A Practical Approach to Design, Implementation, and Management. 4th edition. Addison Wesley, United States of America.

[5] Fajar, 2002. Mahasiswa Dan Budaya Akademik, Rineka, Bandung.

[6] Kurnia, Tedi.; Destiani, Dini; Supriatna.A.D. (2012). Perancangan Sistem Informasi Akademik Nilai Siswa Berbasis Web (Studi Kasus : SMK Ciledug Al-Musaddadiyah Garut).
Jurnal STT-Garut.Vol.09, No.17, hal. 1-9. ISSN : 2302-7339.

[7] Liatmaja, R. (2013). Sistem Informasi Akademik Berbasis Web Pada Lembaga Bimbingan Belajar Be Excellent Pacitan. Indonesian Jurnal On Networking And Security - ISSN : 23025700 Vol. 2 No. 2, 59.

[8] Marimin, dkk. 2005. Sistem Informasi Manejemen Sumber Daya Manusia, Gasindo: Jakarta.

[9] Membara. E.P, Yulia Liza, Kanedi Indra. (2014). Sistem Informasi Akademik Smp Negeri 2 Talang Empat Berbasis Web. Jurnal Infotama Vol. 10, No. 1 hal. 72-80.

[10] Setiyawan, A. (2013). Pembuatan Sistem Informasi Akademik Berbasis Web. Indonesian Journal On Networking And Security - ISSN : 2302-5700, 2. Tohari, H. (2014). astah. Madiun: Andi.

[11] Suzanto boy dan Sidharta Iwan. 2015. Pengukuran End - User computing satisfaction Atas Penggunaan Sistem informasi akademik. Jurnal Ekonomi, Bisnis \& enterpreunership Vol.9, No.1, hal. 16-28.

[12] Yakub. 2012. Pengantar Sistem Informasi. Graha Ilmu : Yogyakarta. 